\title{
Role of single nucleotide polymorphisms of DNA repair genes in susceptibility to pancreatic cancer in Chinese population
}

\author{
M.F. Ying and R. Zhao \\ Department of Pharmacy, Sir Run Run Shaw Hospital, School of Medicine, \\ Zhejiang University, Hangzhou, China \\ Corresponding author: R. Zhao \\ E-mail: zhaozruii@163.com \\ Genet. Mol. Res. 15 (1): gmr.15017273 \\ Received August 8, 2015 \\ Accepted December 11, 2015 \\ Published March 18, 2016 \\ DOI http://dx.doi.org/10.4238/gmr.15017273
}

\begin{abstract}
We conducted a case-control study to investigate the role of ERCC1-ERCC5 gene polymorphisms in the risk of pancreatic cancer. This study included 195 patients who were newly diagnosed with histopathologically confirmed primary pancreatic cancer, and 254 controls were recruited from Sir Run Run Shaw Hospital, between January 2012 and December 2014. Genotyping of ERCC1 rs3212986 and rs11615, ERCC2 rs13181, ERCC3 rs4150441, ERCC4 rs6498486, and ERCC5 rs2094258 polymorphisms was carried out using polymerase chain reaction coupled with restriction fragment length polymorphism. Unconditional logistic regression analyses showed that the TT genotype of ERCC1 rs3212986 was associated with an increased risk of pancreatic cancer, and the OR $(95 \% \mathrm{Cl})$ was 2.26 (1.21-4.22). However, we did not find a significant association between ERCC1 rs11615, ERCC2 rs13181, ERCC3 rs4150441, ERCC4 rs6498486, and ERCC5 rs2094258 polymorphisms and risk of pancreatic cancer. In summary, we found that the presence of the ERCC1 rs3212986 polymorphism correlated with an increased risk of pancreatic cancer.
\end{abstract}

Key words: ERCC1-ERCC5; Polymorphism; Pancreatic cancer 


\section{INTRODUCTION}

Pancreatic cancer is one of the fatal malignant tumors worldwide. It is reported that pancreatic cancer is associated with an overall poor survival, with the 5-year survival rate less than $5 \%$ even after surgical intervention and chemotherapy (Jemal et al., 2007; Tanaka et al., 2011; Nakao et al., 2012). It is well known that pancreatic cancer is a complex disease and involves a multifactorial process (Nakao et al., 2012; Vaccaro et al., 2012). Pancreatic cancer can be caused by many environmental factors, such as alcohol intake, smoking tobacco, body mass index, diabetes mellitus, and a family history of pancreatic cancer in the first relatives (Lowenfels and Maisonneuve, 2006; Luo et al., 2007). However, not all individuals who are exposed to risk factors suffer from pancreatic cancer, suggesting that genetic factors may contribute to the development of this disease.

Efficient DNA repair is required for preventing propagation of errors in the genome and for maintaining genomic stability. Repairing DNA damage involves more than 130 genes and several molecular pathways, including nucleotide excision repair (NER), base-excision repair, homologous recombination, and non-homologous end joining (Popanda et al., 2004). The NER process includes steps of damage recognition, damage demarcation and unwinding, damage incision, and new strand ligation, all of which require corresponding functional proteins (Nouspikel, 2009). Polymorphisms in DNA repair genes may cause defects in DNA repair and then influence an individual's susceptibility to carcinogenesis (Lunn et al., 1999). ERCC2 and ERCC3 participate in the damage unwinding process (Evans et al., 1997; Coin et al., 2007); ERCC1, ERCC4, and ERCC5 are involved in DNA damage incision (Matsunaga et al., 1995; Enzlin and Schärer, 2002). Until now, no study has yet been conducted to investigate the association between ERCC1-ERCC5 gene polymorphisms and the risk of developing pancreatic cancer. Therefore, we conducted a case-control study to investigate the role of ERCC1-ERCC5 gene polymorphisms in the risk of pancreatic cancer.

\section{MATERIAL AND METHODS}

\section{Subjects}

This study included 217 patients with newly diagnosed, histopathologically confirmed primary pancreatic cancer, recruited from Sir Run Run Shaw Hospital, between January 2012 and December 2014. Patients who had primary tumors other than pancreatic cancer, tumors of unknown origin or those that were histopathologically diagnosed as cancers other than pancreatic cancer were excluded. Finally, 195 patients with pancreatic cancer were included in our study, and the participation rate was $89.86 \%$.

The study also included 272 healthy adult subjects without pancreatic cancer that were randomly recruited from individuals who came to receive regular health check-ups at Sir Run Run Shaw Hospital between January 2012 and December 2014. Moreover, individuals who had chronic diseases of the brain, and severe endocrinological, metabolic, and nutritional diseases were excluded from the control groups. Finally, 254 control subjects were included in our study, and the participation rate was $93.38 \%$.

The demographic and clinical information of patients with pancreatic cancer and control subjects were collected from a self-designed questionnaire and medical records, including gender, age, habits of tobacco smoking and alcohol drinking, body mass index, type 2 diabetes, and family history of pancreatic cancer in the first relatives. All patients with pancreatic cancer and control 
subjects signed written informed consents before enrolling into our study. The protocol of this study was approved by the Ethics Committee of Sir Run Run Shaw Hospital.

\section{Genotyping}

Peripheral blood samples $(2 \mathrm{~mL})$ drawn from patients with pancreatic cancer and from control subjects were stored at $-80^{\circ} \mathrm{C}$ until required. Genomic DNA was extracted from the peripheral blood samples using the TIANamp Blood DNA Kit (Tiangen Biotech, Beijing, China). After extraction, genotyping of ERCC1 rs3212986 and rs11615, ERCC2 rs13181, ERCC3 rs4150441, ERCC4 rs6498486, and ERCC5 rs2094258 polymorphisms were carried out using polymerase chain reaction $(\mathrm{PCR})$ coupled with restriction fragment length polymorphism. Primer sequences for the ERCC1 rs3212986 and ERCC2 rs13181 polymorphisms were designed using the Primer premier v5.0 software (Applied Biosystems). The reaction conditions for PCR started with one cycle of DNA denaturation at $94^{\circ} \mathrm{C}$ for $4 \mathrm{~min}$, followed by 30 cycles of denaturation at $94^{\circ} \mathrm{C}$ for 30 $\mathrm{s}, 60^{\circ} \mathrm{C}$ for $30 \mathrm{~s}, 72^{\circ} \mathrm{C}$ for $30 \mathrm{~s}$, and a final extension at $72^{\circ} \mathrm{C}$ for $7 \mathrm{~min}$. The PCR products were analyzed by electrophoresis on a $2 \%$ agarose gel stained with ethidium bromide and visualized under UV light. For quality control, blinded genotyping analysis was performed.

\section{Statistical analysis}

The statistical differences of demographic and clinical characteristics between patients with pancreatic cancer and controls were tested by the chi-square test. The distribution of genotypes in cases and controls was tested for deviation from the Hardy-Weinberg equilibrium (HWE). The distribution of genotypes of ERCC1 rs3212986 and rs11615, ERCC2 rs13181, ERCC3 rs4150441, ERCC4 rs6498486, and ERCC5 rs2094258 polymorphisms in controls was tested for deviation from the HWE. We used the chi-square test to examine differences in genotype distribution between patients with pancreatic cancer and controls. The odds ratios (ORs) and 95\% confidence intervals (Cls) were evaluated for association between RCC1 rs3212986 and rs11615, ERCC2 rs13181, ERCC3 rs4150441, ERCC4 rs6498486, and ERCC5 rs2094258 polymorphisms and the risk of pancreatic cancer using logistic regression models adjusted for confounding factors. $\mathrm{P}<0.05$ was considered to be statistically significant. Statistical analysis was conducted using the SPSS 21.0 package (SPSS Inc., Chicago, IL, USA).

\section{RESULTS}

The demographic and clinical characteristics of patients with pancreatic cancer and controls are shown in Table 1. The chi-square test showed no significant association in age, gender, body mass index, and type 2 diabetes, between patients with pancreatic cancer and controls $(P>0.05)$. When comparing with control subjects, patients with pancreatic cancer were more likely to be smokers, drinkers and to have a family history of pancreatic cancer among their first relatives $(P<0.05)$.

The genotype distributions of ERCC1 rs3212986 and rs11615, ERCC2 rs13181, ERCC3 rs4150441, ERCC4 rs6498486, and ERCC5 rs2094258 polymorphisms are shown in Table 2. The genotype distributions of ERCC1 rs3212986 and rs11615, ERCC3 rs4150441, ERCC4 rs6498486, and ERCC5 rs2094258 polymorphisms were found to be confirmed with HWE in the controls, and the $P$ values were $0.49,0.36,0.37,0.57$, and 0.40 , respectively. However, the genotype distribution 
of ERCC2 rs13181 was not in line with the HWE in the controls $(P<0.01)$. Using the chi-square test, we found a significant difference in the genotype distributions of ERCC1 rs3212986 between patients with pancreatic cancer and controls $\left(\chi^{2}=7.86, P\right.$ value $\left.=0.02\right)$. Unconditional logistic regression analyses showed that the TT genotype of ERCC1 rs3212986 was associated with an increased risk of pancreatic cancer, and the OR $(95 \% \mathrm{Cl})$ was $2.26(1.21-4.22)$. However, we did not find a significant association between the ERCC1 rs11615, ERCC2 rs1318, ERCC3 rs4150441, ERCC4 rs6498486 and ERCC5 rs2094258 polymorphisms and the risk of pancreatic cancer.

\begin{tabular}{|c|c|c|c|c|c|c|}
\hline Variables & Patients & $\%$ & Controls & $\%$ & $\chi^{2}$ test & $\mathrm{P}$ value \\
\hline \multicolumn{7}{|l|}{ Age, years } \\
\hline$\leq 60$ & 83 & 42.56 & 120 & 47.24 & & \\
\hline$>60$ & 112 & 57.44 & 134 & 52.76 & 0.98 & 0.32 \\
\hline \multicolumn{7}{|l|}{ Gender } \\
\hline Male & 139 & 71.28 & 159 & 62.60 & & \\
\hline Female & 56 & 28.72 & 95 & 37.40 & 3.73 & 0.06 \\
\hline \multicolumn{7}{|c|}{ Tobacco smoking } \\
\hline Never & 87 & 44.62 & 143 & 56.30 & & \\
\hline Ever & 108 & 55.38 & 111 & 43.70 & 6.03 & 0.01 \\
\hline \multicolumn{7}{|c|}{ Alcohol drinking } \\
\hline Never & 96 & 49.23 & 158 & 62.20 & & \\
\hline Ever & 99 & 50.77 & 96 & 37.80 & 7.56 & 0.01 \\
\hline \multicolumn{7}{|c|}{ Body Mass Index (BMI) } \\
\hline$\leq 24$ & 118 & 60.51 & 176 & 69.29 & & \\
\hline$>24$ & 77 & 39.49 & 78 & 30.71 & 3.76 & 0.06 \\
\hline \multicolumn{7}{|c|}{ Type 2 diabetes } \\
\hline No & 34 & 17.44 & 34 & 13.39 & & \\
\hline Yes & 161 & 82.56 & 220 & 86.61 & 1.41 & 0.24 \\
\hline \multicolumn{7}{|c|}{ Family history of pancreatic cancer in the first relatives } \\
\hline No & 189 & 96.92 & 254 & 100.00 & & \\
\hline Yes & 6 & 3.08 & 0 & 0.00 & 7.92 & 0.01 \\
\hline
\end{tabular}

\begin{tabular}{|c|c|c|c|c|c|c|c|c|c|}
\hline Polymorphisms & Cases & $\%$ & Controls & $\%$ & HWE & $\chi^{2}$ test & $\mathrm{P}$ value & Adjusted OR $(95 \% \mathrm{Cl})^{1}$ & $P$ value \\
\hline \multicolumn{10}{|c|}{ ERCC1 rs3212986 } \\
\hline GG & 62 & 31.79 & 106 & 41.73 & & & & 1.0 (Ref.) & - \\
\hline $\mathrm{GT}$ & 97 & 49.74 & 120 & 47.24 & & & & $1.38(0.89-2.13)$ & 0.12 \\
\hline TT & 37 & 18.97 & 28 & 11.02 & 0.49 & 7.86 & 0.02 & $2.26(1.21-4.22)$ & 0.006 \\
\hline \multicolumn{10}{|l|}{ ERCC1 rs11615 } \\
\hline $\mathrm{CC}$ & 90 & 46.15 & 126 & 49.61 & & & & 1.0 (Ref.) & - \\
\hline CT & 88 & 45.13 & 110 & 43.31 & & & & $1.12(0.74-1.68)$ & 0.57 \\
\hline TT & 17 & 8.72 & 18 & 7.09 & 0.36 & 0.73 & 0.69 & $1.32(0.60-2.88)$ & 0.44 \\
\hline \multicolumn{10}{|l|}{ ERCC2 rs13181 } \\
\hline TT & 113 & 57.95 & 159 & 62.60 & & & & 1.0 (Ref.) & - \\
\hline TG & 56 & 28.72 & 70 & 27.56 & & & & $1.13(0.72-1.76)$ & 0.59 \\
\hline GG & 26 & 13.33 & 25 & 9.84 & $<0.01$ & 1.63 & 0.44 & $1.46(0.77-2.79)$ & 0.21 \\
\hline \multicolumn{10}{|c|}{ ERCC3 rs4150441 } \\
\hline GG & 68 & 34.87 & 98 & 38.58 & & & & 1.0 (Ref.) & - \\
\hline $\mathrm{GA}$ & 88 & 45.13 & 114 & 44.88 & & & & $1.11(0.72-1.72)$ & 0.61 \\
\hline AA & 38 & 19.49 & 42 & 16.54 & 0.37 & 0.95 & 0.62 & $1.30(0.73-2.31)$ & 0.33 \\
\hline \multicolumn{10}{|c|}{ ERCC4 rs6498486 } \\
\hline AA & 101 & 51.79 & 141 & 55.51 & & & & 1.0 (Ref.) & - \\
\hline$A C$ & 79 & 40.51 & 98 & 38.58 & & & & $1.13(0.74-1.70)$ & 0.55 \\
\hline $\mathrm{CC}$ & 15 & 7.69 & 14 & 5.51 & 0.57 & 1.20 & 0.55 & $1.50(0.64-3.50)$ & 0.30 \\
\hline \multicolumn{10}{|c|}{ ERCC5 rs2094258 } \\
\hline GG & 87 & 44.62 & 117 & 46.06 & & & & 1.0 (Ref.) & - \\
\hline $\mathrm{GA}$ & 92 & 47.18 & 115 & 45.28 & & & & $1.08(0.71-1.62)$ & 0.71 \\
\hline AA & 16 & 8.21 & 22 & 8.66 & 0.40 & 0.16 & 0.92 & $0.98(0.45-2.08)$ & 0.95 \\
\hline
\end{tabular}

${ }^{1}$ Adjusted for gender, age, and tobacco smoking and alcohol drinking habits. 
We conducted an analysis of the association between ERCC1 rs3212986 polymorphism and the demographic characteristics of individuals at risk of developing pancreatic cancer, stratified by tobacco smoking and alcohol drinking (Table 3). However, no significant interaction was found between the ERCC1 rs1800896 polymorphism and tobacco smoking and alcohol drinking in the risk of pancreatic cancer.

Table 3. Association between ERCC1 rs 3212986 and demographic characteristics of individuals at risk of developing pancreatic cancer.

\begin{tabular}{|c|c|c|c|c|c|c|}
\hline \multirow[t]{2}{*}{ Variables } & \multicolumn{2}{|c|}{ GG } & \multicolumn{2}{|c|}{$\mathrm{GT}+\mathrm{TT}$} & \multirow[t]{2}{*}{ OR $(95 \% \mathrm{Cl})^{1}$} & \multirow[t]{2}{*}{$P$ value } \\
\hline & Patients & Controls & Patients & Controls & & \\
\hline \multicolumn{7}{|c|}{ Tobacco smoking } \\
\hline Ever & 27 & 59 & 60 & 84 & $1.56(0.86-2.86)$ & 0.12 \\
\hline Never & 35 & 47 & 73 & 64 & $1.53(0.85-2.76)$ & 0.13 \\
\hline \multicolumn{7}{|c|}{ Alcohol drinking } \\
\hline Ever & 30 & 65 & 66 & 93 & $1.54(0.87-2.73)$ & 0.11 \\
\hline Never & 32 & 41 & 67 & 55 & $1.56(0.84-2.92)$ & 0.13 \\
\hline
\end{tabular}

${ }^{1}$ Adjusted for gender and age.

\section{DISCUSSION}

Genetic susceptibility to cancers has attracted growing attention to investigate gene polymorphisms associated with cancer development. Carcinogenic compounds exert their effect by causing direct or indirect DNA damage or alterations. The capacity to repair DNA damage is under genetic control and may be an important endogenous factor influencing the susceptibility of cancer. In the present study, we suggest that the ERCC1 rs3212986 polymorphism contributes to the development of pancreatic cancer in a Chinese population.

NER is an important mechanism of the DNA repair pathway that maintains genomic integrity by removing DNA inter-strand crosslinks (Neumann et al., 2005; Wu et al., 2005). The product of the ERCC1 gene is a key rate-limiting enzyme acting in the NER process. ERCC1 is a subunit of the NER complex, which interacts with XPA, XPF and/or RPA, guiding the 5' cleavage activity in the NER pathway (Sijbers et al., 1996; Volker et al., 2001). Cells from ERCC1-deficient mice are associated with a high mutation frequency, an elevated level of genomic instability, a reduced frequency of S-phase-dependent illegitimate chromosome exchange, and a response adopted by rodent cells to prevent the accumulation of DNA double strand breaks (Melton et al., 1998). Therefore, polymorphisms in ERCC1 could influence susceptibility to cancers, including pancreatic cancer.

Previous studies have indicated that ERCC1 rs3212986 polymorphisms are associated with development of several kinds of cancers, such as breast cancer, colorectal cancer, lung cancer and gliomas. Guo et al. (2015) conducted a meta-analysis with 3308 patients and 3242 controls from eight studies, and reported that individuals with the ERCC1 rs3212986 polymorphism were associated with an increased risk of breast cancer in Caucasians. Hou et al. (2014) conducted a study in a Chinese population, and reported that the ERCC1 rs3212986 polymorphism is associated with a risk of colorectal cancer. Zhu et al. (2014) conducted a meta-analysis with 11 case-control studies, but they did not find any association between the ERCC1 rs3212986 polymorphism and development of lung cancer. Yuan et al. (2014) also conducted a meta-analysis with seven studies, and reported that the ERCC1 rs3212986 polymorphism correlated with the risk of non-glioblastoma multiforme. The association between the ERCC1 rs3212986 polymorphism 
and the risk of pancreatic cancer has been reported in only one previous study (McWilliams et al., 2008). However, McWilliams et al. (2008) did not find a significant association between the ERCC1 rs3212986 polymorphism and risk of pancreatic cancer.

Two limitations should be considered in our study. First, the patients and controls were selected from only one hospital introducing a possible selection bias in our study. Second, the sample size of this study is relatively small, which may limit the statistical power of finding a difference between the two groups. Therefore, further large-scale studies in different ethnic groups are greatly needed to confirm our results.

In summary, we found that the ERCC1 rs3212986 polymorphism correlated with an increased risk of pancreatic cancer in a Chinese population. Future studies with a large sample size may contribute to further elucidate the impact of ERCC1 rs3212986 polymorphism on the risk of pancreatic cancer.

\section{REFERENCES}

Coin F, Oksenych V and Egly JM (2007). Distinct roles for the XPB/p52 and XPD/p44 subcomplexes of TFIIH in damaged DNA opening during nucleotide excision repair. Mol. Cell 26: 245-256. http://dx.doi.org/10.1016/j.molcel.2007.03.009

Enzlin JH and Schärer OD (2002). The active site of the DNA repair endonuclease XPF-ERCC1 forms a highly conserved nuclease motif. EMBO J. 21: 2045-2053. http://dx.doi.org/10.1093/emboj/21.8.2045

Evans E, Moggs JG, Hwang JR, Egly JM, et al. (1997). Mechanism of open complex and dual incision formation by human nucleotide excision repair factors. EMBO J. 16: 6559-6573. http://dx.doi.org/10.1093/emboj/16.21.6559

Guo XG, Wang Q, Xia Y and Zheng L (2015). The C8092A polymorphism in the ERCC1 gene and breast carcinoma risk: a meta-analysis of case-control studies. Int. J. Clin. Exp. Med. 8: 3691-3699.

Hou R, Liu Y, Feng Y, Sun L, et al. (2014). Association of single nucleotide polymorphisms of ERCC1 and XPF with colorectal cancer risk and interaction with tobacco use. Gene 548: 1-5. http://dx.doi.org/10.1016/j.gene.2014.05.025

Jemal A, Siegel R, Ward E, Murray T, et al. (2007). Cancer statistics, 2007. CA Cancer J. Clin. 57: 43-66. http://dx.doi. org/10.3322/canjclin.57.1.43

Lowenfels $A B$ and Maisonneuve P (2006). Epidemiology and risk factors for pancreatic cancer. Best Pract. Res. Clin. Gastroenterol. 20: 197-209. http://dx.doi.org/10.1016/j.bpg.2005.10.001

Lunn RM, Langlois RG, Hsieh LL, Thompson CL, et al. (1999). XRCC1 polymorphisms: effects on aflatoxin B1-DNA adducts and glycophorin A variant frequency. Cancer Res. 59: 2557-2561.

Luo J, Iwasaki M, Inoue M, Sasazuki S, et al.; JPHC Study Group (2007). Body mass index, physical activity and the risk of pancreatic cancer in relation to smoking status and history of diabetes: a large-scale population-based cohort study in Japan--the JPHC study. Cancer Causes Control 18: 603-612. http://dx.doi.org/10.1007/s10552-007-9002-z

Matsunaga T, Mu D, Park CH, Reardon JT, et al. (1995). Human DNA repair excision nuclease. Analysis of the roles of the subunits involved in dual incisions by using anti-XPG and anti-ERCC1 antibodies. J. Biol. Chem. 270: 20862-20869. http://dx.doi.org/10.1074/jbc.270.35.20862

McWilliams RR, Bamlet WR, Cunningham JM, Goode EL, et al. (2008). Polymorphisms in DNA repair genes, smoking, and pancreatic adenocarcinoma risk. Cancer Res. 68: 4928-4935.

Melton DW, Ketchen AM, Núñez F, Bonatti-Abbondandolo S, et al. (1998). Cells from ERCC1-deficient mice show increased genome instability and a reduced frequency of S-phase-dependent illegitimate chromosome exchange but a normal frequency of homologous recombination. J. Cell Sci. 111: 395-404.

Nakao M, Hosono S, Ito H, Watanabe M, et al. (2012). Selected polymorphisms of base excision repair genes and pancreatic cancer risk in Japanese. J. Epidemiol. 22: 477-483. http://dx.doi.org/10.2188/jea.JE20120010

Neumann AS, Sturgis EM and Wei Q (2005). Nucleotide excision repair as a marker for susceptibility to tobacco-related cancers: a review of molecular epidemiological studies. Mol. Carcinog. 42: 65-92. http://dx.doi.org/10.1002/mc.20069

Nouspikel T (2009). DNA repair in mammalian cells : Nucleotide excision repair: variations on versatility. Cell. Mol. Life Sci. 66: 994-1009. http://dx.doi.org/10.1007/s00018-009-8737-y

Popanda O, Schattenberg T, Phong CT, Butkiewicz D, et al. (2004). Specific combinations of DNA repair gene variants and increased risk for non-small cell lung cancer. Carcinogenesis 25: 2433-2441. http://dx.doi.org/10.1093/carcin/bgh264

Sijbers AM, de Laat WL, Ariza RR, Biggerstaff M, et al. (1996). Xeroderma pigmentosum group F caused by a defect in a structure-specific DNA repair endonuclease. Cell 86: 811-822. http://dx.doi.org/10.1016/S0092-8674(00)80155-5 
Tanaka M, Okazaki T, Suzuki H, Abbruzzese JL, et al. (2011). Association of multi-drug resistance gene polymorphisms with pancreatic cancer outcome. Cancer 117: 744-751. http://dx.doi.org/10.1002/cncr.25510

Vaccaro V, Gelibter A, Bria E, lapicca P, et al. (2012). Molecular and genetic bases of pancreatic cancer. Curr. Drug Targets 13: 731-743. http://dx.doi.org/10.2174/138945012800564077

Volker M, Moné MJ, Karmakar P, van Hoffen A, et al. (2001). Sequential assembly of the nucleotide excision repair factors in vivo. Mol. Cell 8: 213-224. http://dx.doi.org/10.1016/S1097-2765(01)00281-7

Wu Q, Christensen LA, Legerski RJ and Vasquez KM (2005). Mismatch repair participates in error-free processing of DNA interstrand crosslinks in human cells. EMBO Rep. 6: 551-557. http://dx.doi.org/10.1038/sj.embor.7400418

Yuan G, Gao D, Ding S and Tan J (2014). DNA repair gene ERCC1 polymorphisms may contribute to the risk of glioma Tumour Biol. 35: 4267-4275. http://dx.doi.org/10.1007/s13277-013-1557-6

Zhu J, Hua RX, Jiang J, Zhao LQ, et al. (2014). Association studies of ERCC1 polymorphisms with lung cancer susceptibility: a systematic review and meta-analysis. PLoS One 9: e97616. http://dx.doi.org/10.1371/journal.pone.0097616 